\title{
Intragenic complementation between Escherichia coli trp repressors with different defects in the tryptophan-binding pocket
}

(Repressor; aporepressor; site-directed mutagenesis; protein-DNA interaction; protein engineering)

\author{
Norunn Storbakk ${ }^{a}$, Dale L. Oxender ${ }^{b *}$ and M. Raafat El-Gewely ${ }^{a}$ \\ “ Department of Biotechnology. Institute of Medical Biology, University of Tromso. N-9001 Tromso (Norway), and "Department of Biological Chemistry, Uni- \\ versity of Michigan, Ann Arbor. MI 48I09-0606 (USA)
}

Received by F. Barany: 30 September 1991; Revised/Accepted: 6 February/17 February 1992; Received at publishers: 31 March 1992

\section{SUMMARY}

Site-directed mutagenesis of the $t r p R$ gene (encoding the $\operatorname{trp}$ repressor, $\operatorname{TrpR}$ ) was used to replace Gly ${ }^{85}$ with tryptophan (Trp or W), in order to place Trp near its normal location in the L-tryptophan(L-W)-binding pocket. The resulting mutant protein (G85W) exhibits weak, but significant repressor activity in vivo that is independent of the presence of $L-W$ in the media. This mutant negatively complements the chromosomal wild type (wt), but does not negatively complement either the wt or the super-repressor, E49K, when any of these alleles is expressed on a multicopy plasmid. Activity of the mutant repressor, G85W, when produced in vivo together with T44M, approaches that of the wt repressor. This result presumably reflects complementation between the two mutant polypeptides. Similar results are obtained when G85R or G85K are combined with T44M in vivo, but not when G85W is replaced by G85E. The level of repression is dependent on the presence of $\mathrm{L}-\mathrm{W}$ in the media. The TrpR with two mutations altering both Gly ${ }^{85}$ (G85W, G85R, G85E or G85K) and Thr ${ }^{44}$ (T44M) has no repressor activity. These results suggest a type of site-specific intragenic complementation where only certain alterations at Gly ${ }^{85}$ complement T44M. In this study, a positive charge or an indole ring appears to be required for the observed intragenic complementation.

\section{INTRODUCTION}

Tryptophan repressor (TrpR) is a dimer of two identical 107-aa polypeptide chains encoded by the $t r p R$ gene (Gunsalus and Yanofsky, 1980; Joachimiak et al., 1983; El-Gewely, 1991). The aporepressor is activated by the binding of two molecules of L-W (Arvidson et al., 1986),

Correspondence to: Dr. M. R. El-Gewely, Department of Biotechnology, Institute of Medical Biology, University of Tromsø, N-9001 Tromsø (Norway) Tel. (47-83)44654; Fax (47-83)80850.

* Pressent address: Department of Biotechnology, Warner-Lambert Company, 2800 Plymouth Rd., Ann Arbor, MI 48106-1047 (USA) Tel. (313) 996-7601. and binds a variety of indole analogues (Marmorstein et al., 1987; Lawson and Sigler, 1988; Marmorstein and Sigler, 1989). Mutant $t r p$ aporepressor has also been shown to form heterodimers in vitro in the absence of $t r p O$ (Graddis et al., 1988). TrpR repressor has been subjected to mutation studies (Kelley and Yanofsky, 1985), and to secondsite reversion studies (Klig et al., 1988b).

Abbreviations: aa, amino acid(s); Ap, ampicillin; $\beta \mathrm{Gal}, \beta$-galactosidase; bp, base pair(s); Cm, chloramphenicol; G85W, G85R, G85E, G85K, mutant proteins in which Gly ${ }^{85}$ was replaced by Trp, Arg, Glu and Lys, respectively; HPLC, high-performance liquid chromatography; L-W, Ltryptophan as co-repressor; nt, nucleotide(s); oligo, oligodeoxyribonucleotide; Tc, tetracycline; T44M, mutant protein in which $\mathrm{Thr}^{44}$ was replaced by Met; TrpR, $t r p$ repressor; $t r p R$, gene encoding TrpR; wt, wild type; XGal, 5-bromo-4-chloro-3-indolyl- $\beta$-D-galactopyranoside. 
TrpR can specifically interact with four similar but unlinked operator regions, for operons $\operatorname{trp} R$ (autoregulated), $\operatorname{trpEDCBA}, \operatorname{aroH}$, and the recently discovered gene $\mathrm{mtr}$ encoding a Trp-specific permease (Gunsalus and Yanofsky, 1980; Grove and Gunsalus, 1987; Klig et al., 1988a; Heatwole and Somerville, 1991; Sarsero et al., 1991). Recently the suggestion has been made by Staacke et al. (1990) that the TrpR/trpO complex should be reinvestigated in view of their proposed rules for DNA-protein interaction (Lehming et al., 1990). According to Staacke et al. (1990), two dimers of the TrpR bind simultaneously to the trpO, implying some protein-protein interaction between the two innermost subunits of the dimers during DNA binding.

The crystal structures of TrpR (Schevitz et al., 1985), trp aporepressor (Zhang et al., 1987), trp pseudorepressor (Lawson and Sigler, 1988), and TrpR/trpO complex (Otwinowski et al., 1988) have been resolved. The crystal structure shows that in the active repressor, $\mathrm{L}-\mathrm{W}$ is bound to aa of both TrpR subunits in the dimer making the DNA 'reading heads', corresponding to a helix-turn-helix motif, to move away from the core to fit the successive major grooves on the DNA. The L-W indole ring makes hydrophobic interactions with side chains of $\mathrm{Arg}^{84}$ and $\mathrm{Arg}^{54}$ on one subunit. The other subunit is connected by $\mathrm{H}$-bonds between the L-W amino group and carboxyl groups on the C-terminal end of helix B. Also, the hydroxyl group of $\mathrm{Thr}^{44}$, located in the hinge region between helices B and C, makes a H-bond to L-W (Zhang et al., 1987).

Considerable conservation of the aa sequence has been found in the helix-turn-helix region of prokaryotic repressors. However, a striking anomaly has been noted for the $\mathrm{Gly}^{85}$ in the TrpR. The corresponding position in most other repressors is occupied by a bulky hydrophobic aa, and often Trp (Pabo and Sauer, 1984; Harrison and Aggarwal, 1990). It is also worth noting that in all the eukaryotic systems examined, this position in the helix-turn-helix motif is always occupied by $\operatorname{Trp}$ (Scott et al., 1989; Gehring et al., 1990).

In this study a Trp residue was covalently inserted into its normal binding pocket to examine the role of the bulky indole ring in activating the aporepressor. A covalently bound Trp would lack both free $\alpha$-carboxyl and $\alpha$-amino groups. Marmorstein and Sigler (1989) have examined the binding of $\mathrm{L}-\mathrm{W}$ analogues to aporepressor and have found that the $\alpha$-carboxyl group enhances, but is not essential for operator binding. The free $\alpha$-amino group of $L-W$ is required to orient the co-repressor properly in its binding pocket (Marmorstein and Sigler, 1989). Presumably, the orientation of the Trp molecule inserted near the L-W binding pocket will be restricted. The in vivo repressor activity of $\mathrm{G} 85 \mathrm{~W}$ was compared with the activities of mutant repressors with other changes at position 85 (G85R, G85K. and G85E), both in the presence and absence of the corepressor. We also examined the ability of G85W, G85R, G85K, and G85E to complement the T44M mutant repressor. Finally the repressor activities of double mutants which contained one mutation at position 85 (G85W, G85R, G85E or G85K) and a second mutation at position 44 (T44M) were examined.

\section{RESULTS AND DISCUSSION}

\section{(a) Repressor activity of G85W and other trpR alleles}

The repressor activity of all the $t r p R$ mutants was measured in terms of their ability to repress the $\beta \mathrm{Gal}$ activity of the trp-lac $Z$ fusion. The activity of G85W and T44M repressors was also measured in two different multiple copy plasmids (pACYC184 and pBR322). G85W gave approximately $90 \%$ repressor activity (Table I), and T44M (Tables II and III) showed only $59 \%$ repression. We consider the differences in copy number between pBR322 and pACYC184 to be of minor importance in this study. Placing the G85W repressor gene in the opposite direction, downstream from $\mathrm{Tc}^{\mathrm{R}}$ promoter, resulted in a total lack of repressor activity (M.R.El-G. unpublished data).

TABLE I

Rspression by the G85W mutant

\begin{tabular}{lllrc}
\hline No. & TrpR $^{a}$ & Plasmid $^{\text {b }}$ & $\beta_{\text {Gal }}$ & \% repression \\
\hline 1 & $R^{-}$ & - & 14825 & 0 \\
2 & $R^{+}$ & pACYC184 & 4 & 100 \\
3 & none & pBR322 & 15597 & 0 \\
4 & none & pACYC184 & 11339 & 24 \\
5 & G85W & pBR322 & 1185 & 92 \\
6 & G85W & pACYC184 & 1621 & 89 \\
\hline
\end{tabular}

" $R^{+}$indicates wt trp $R^{+}$carried on plasmid pACYC184. $R^{-}$indicates no wt trpR (only trpR2 mutation in the host). 'None' indicates plasmid without $w p R^{+}$. Construction of plasmid with $\mathrm{G} 85 \mathrm{~W}$ alleles as described in Table II, footnote a.

b CY15075 \{W3110 maA2 $\Delta l a c$ U169 trpR2(גTLF1)\} (Yanofsky and Horn, 1981) was transformed by pACYC184 or pBR322 containing $t r p R$ wt or G85W alleles. CY15075 lacks TrpR activity and has $\beta \mathrm{Gal}$ production under trpR regulation.

c Units of $\beta$ Gal activity in the presence of $\mathrm{L}-\mathrm{W}(20 \mu \mathrm{g} / \mathrm{ml})$. Cells were grown in minimal media (Vogel and Bonner, 1956). Cm $(15 \mu \mathrm{g} / \mathrm{ml})$ or Ap $(20 \mu \mathrm{g} / \mathrm{ml})$ was added to the glucose minimal media containing $0.2 \%$ acidhydrolyzed casein. $\beta \mathrm{Gal}$ assays were carried out as described by Miller (1972). All assays were made in triplicate and repeated twice. Bacto tryptone plates ( $10 \mathrm{~g}$ Bacto tryptone $/ 5 \mathrm{~g} \mathrm{NaCl} / 2 \mathrm{~g}$ glucose $/ 15 \mathrm{~g}$ agar, all per liter), containing XGal $(40 \mu \mathrm{g} / \mathrm{ml})$, phenylethylthio- $\beta$-D-galactoside $(80 \mu \mathrm{g} / \mathrm{ml})$, and appropriate antibiotics were used as indicator plates to detect the $\beta \mathrm{Gal}$ activity of the mutants. Bacterial strains were otherwise grown in LB broth (Miller, 1972) in the presence of $\mathrm{Cm}(15 \mu \mathrm{g} / \mathrm{ml})$ and/ or Ap $(20 \mu \mathrm{g} / \mathrm{ml})$. LB was also used for M13trpR growth.

d $\%$ repression $=100-\left(\beta \mathrm{Gal}\right.$ value $\left.{ }^{c}\right) \times 100 / 14825$. The $14825 \beta \mathrm{Gal}$ units represent the activity of the control, CY15075 containing no TrpR (see footnote b). This control value (14825) was used in Tables I-III. 
TABLE II

The interaction between G85W and different trpR alleles

\begin{tabular}{|c|c|c|c|c|c|c|}
\hline \multirow[t]{2}{*}{ No. $^{a}$} & \multirow[t]{2}{*}{$\operatorname{TrpR}^{\mathrm{a}}$} & \multirow[t]{2}{*}{ Plasmid $^{\mathbf{b}}$} & \multicolumn{2}{|l|}{$\beta \mathrm{Gal}^{\mathrm{c}}$} & \multirow[t]{2}{*}{$\% d$} & \multirow[t]{2}{*}{ Ratio $^{\circ}$} \\
\hline & & & $+\mathrm{L}-\mathrm{W}$ & no L-W & & \\
\hline 1 & $\mathbf{R}^{+}$ & pACYC184 & 6 & 472 & 100 & 78.6 \\
\hline 2 & $\mathbf{R}^{+} / \mathrm{pBR} 322$ & pACYC184/pBR322 & 34 & 242 & 100 & 7.1 \\
\hline 3 & G85W & pACYCl84 & 1906 & 2219 & 87 & 1.1 \\
\hline 4 & G85W/pACYC184 & pBR322/pACYC184 & 1146 & 1120 & 92 & 1.0 \\
\hline 5 & $\mathbf{G} 85 \mathrm{~W} / \mathbf{R}^{+}$ & pBR322/pACYC184 & 8 & 143 & 100 & 17.9 \\
\hline 6 & $\mathrm{~T} 44 \mathrm{M}$ & pACYCI84 & 6082 & 7974 & 59 & 1.3 \\
\hline 7 & E49K & pACYC184 & 5 & 140 & 100 & 28.0 \\
\hline 8 & R54H & pACYC184 & 7348 & 7532 & 50 & 1.0 \\
\hline 9 & G78S & pACYC184 & 3499 & 2714 & 76 & 0.8 \\
\hline 10 & R84H & pACYC184 & 7340 & 6630 & 50 & 0.9 \\
\hline 11 & G85E & pACYC184 & 8253 & 8405 & 44 & 1.0 \\
\hline 12 & G85R & pACYC184 & 2066 & 2239 & 86 & 1.1 \\
\hline 13 & G85W/T44M & pACYC184/pBR322 & 139 & 1878 & 99 & 13.5 \\
\hline 14 & G85W/E49K & pBR322/pACYC184 & 8 & 122 & 100 & 15.2 \\
\hline 15 & G85W/R54H & pBR322/pACYC184 & 2033 & 2058 & 86 & 1.0 \\
\hline 16 & G85W/G78S & pBR322/pACYC184 & 247 & 928 & 98 & 3.7 \\
\hline 17 & G85W/R84H & pBR322/pACYC184 & 1048 & 2455 & 93 & 2.3 \\
\hline 18 & G85W/G85E & pBR322/pACYCl84 & 1417 & 1729 & 90 & 1.2 \\
\hline 19 & G85W/G85R & pACYC184/pBR322 & 345 & 678 & 97 & 1.9 \\
\hline 20 & G85W/G85W & pBR322/pACYC184 & 370 & 481 & 97 & 1.3 \\
\hline
\end{tabular}

a Mutants 6-12 were produced and reported earlier by Kelley and Yanofsky (1985). Mutant 3 was essentially produced as described by Kunkel (1985). The uracil-containing templates for site-directed mutagenesis were produced in ung ${ }^{-}$dut ${ }^{-}$strain RZ1032 (Kunkel et al., 1987). M13 bacteriophage (Yanisch-Perron et al., 1985) was grown in the $u n g^{+}$dut ${ }^{+}$strains DH5 $5^{\prime}$ or JM101. A mutagenic primer complementary to the (+) strand of M13mplltrpR was synthesized with the internal TCC $\left(\mathrm{Gly}^{85}\right)$ replaced by CCA (Trp): 5' -CAGGCTGTTAGACCAACGCGTAATCGTCGC-3' . This oligo was prepared by the phosphoramidite method with an Applied BioSystem 380A DNA synthesizer, purified by HPLC, phosphorylated with T4 polynucleotide kinase and [ $\gamma^{32}$ P]ATP (Maniatis et al., 1978), and annealed to the ( + ) strand of M13trpR at 50- to 100-fold molar excess. DNA synthesis of the (-) strand was carried out using the Klenow fragment of DNA polymerase I at $0^{\circ} \mathrm{C}$ overnight followed by ligation at $14^{\circ} \mathrm{C}$ overnight. DNA was isolated (Messing, 1983) and sequenced (Sanger et al., 1977) with [ ${ }^{35}$ S ]dCTP (Amersham) (Biggin et al., 1983) to verify the presence of the desired mutations. Gel electrophoresis was performed as described by Sanger and Coulson (1978). RF DNA of mutant M13 trpR was isolated either by CsCldensity gradient centrifugation (El-Gewely, 1988) or alkaline lysis (Birnboim and Doly, 1979), cleaved with BamHI, and the fragment containing trpR was gel-purified (Girvitz et al., 1980) and subcloned into the BamHI site in the Tc ${ }^{\mathrm{R}}$ gene of pACYC184 (Chang and Cohen, 1978) or pBR322 (Bolivar et al., 1977). Competent RR1 cells (Bolivar et al., 1977) were transformed with the constructed plasmids. Transformants were selected on the Cm-LB or Ap-LB agar plates and screened by replica plating on Tc plates. Plasmid DNA was isolated and the orientation of the BamHI fragment in the plasmid was verified by restriction analysis with SalI. The mutant plasmids were transformed into the test strain, CY15075( $\lambda$ TLF) to assay for Trp repressor activity. b CY15075 (see Table I, 1, note b) were transformed by plasmids containing other trpR alleles previously made by Kelley and Yanofsky (1985).

c Units of $\beta \mathrm{Gal}$ activity in the presence ( $+\mathrm{L}-\mathrm{W}$ ) or absence of L-tryptophan (no L-W) $(20 \mu \mathrm{g} / \mathrm{ml})$. Otherwise as in Table I, footnote c.

'Correspond to '\% repression' in Table I, footnote d, calculated from the $+\mathrm{L}-\mathrm{W}$ column.

- The ratio between the repression values in the absence and presence of $L$-tryptophan.

It was assumed that replacing $\mathrm{Gly}^{85}$ in the $\mathrm{L}$-W-binding pocket with a Trp residue (G85W) would partially prevent the collapse of the aporepressor and thus retain some DNA-binding activity. Following this assumption, the level of repression should be maintained irrespective of the presence of $\mathrm{L}-\mathrm{W}$ in the media. Substituting Trp at the position of $\mathrm{Gly}^{85}$ resulted in a mutant with weak repressor activity relative to the wt $\operatorname{TrpR}$. As expected, the activity of G85W was independent of the presence of L-W in the media (Tables II and III). The partial repressor activity of G85W is suggested to be a result of insertion of the bulky indole moiety of Trp near the co-repressor-binding pocket.

$\mathrm{Gly}^{85}$ has been replaced by aa differing in both charge and bulkiness (Kelley and Yanofsky, 1985). Substitution with the positively charged $\mathrm{Arg}^{85}$ gave rise to repressor activity similar to the observed activity of G85W (Tables II and III). The residual repressor activity of G85R may be explained in a similar manner to that for G85W. Both TrpR G85E (negative charge) and TrpR G85K (positive charge) had lost their repressor activity (Table III). For specific binding between the TrpR and DNA to occur, the repressor requires two DNA-binding sites. Certain mutations that alter DNA binding not only result in an inactive repressor; an inactive heterodimer is also often produced when they are combined with the wt repressor, leading to negative complementation (Kelley and Yanofsky, 1985). Position 85 
TABLE III

Site-specific intragenic complementation in $\operatorname{trpR}$ mutants

\begin{tabular}{|c|c|c|c|c|c|c|}
\hline \multirow[t]{2}{*}{ No. } & \multirow[t]{2}{*}{$\operatorname{Trp}^{a}$} & \multirow[t]{2}{*}{ Plasmid $^{b}$} & \multicolumn{2}{|l|}{$\beta \mathrm{Gal}^{\mathrm{c}}$} & \multirow[t]{2}{*}{$\% d$} & \multirow[t]{2}{*}{ Ratio $^{e}$} \\
\hline & & & $+\mathrm{L}-\mathrm{W}$ & no L-W & & \\
\hline 1 & none & pACYC184 & 10130 & 9623 & 31 & 0.9 \\
\hline 2 & $\mathbf{R}^{+}$ & pACYC184 & 6 & 472 & 100 & 78.6 \\
\hline 3 & G85W & pACYC184 & 1816 & 2206 & 88 & 1.2 \\
\hline 4 & G85R & pACYC184 & 1705 & 1498 & 88 & 0.9 \\
\hline 5 & G85E & pACYC184 & 7560 & 7915 & 49 & 1.0 \\
\hline 6 & G85K & pACYC184 & 8806 & 8201 & 40 & 0.9 \\
\hline 7 & $\mathrm{~T} 44 \mathrm{M}$ & pBR322 & 6089 & 7095 & 59 & 1.1 \\
\hline 8 & G85W/T44M & pACYC184/pBR322 & 136 & 1930 & 99 & 14.2 \\
\hline 9 & G85R/T44M & pACYC184/pBR322 & 28 & 456 & 100 & 16.3 \\
\hline 10 & G85E/T44M & pACYC184/pBR322 & 3199 & 6027 & 78 & 1.9 \\
\hline 11 & G85K/T44M & pACYC184/pBR322 & 635 & 2517 & 96 & 3.9 \\
\hline
\end{tabular}

a Alleles at residue 85 were tested against T44M in the CY15075 host (see Table I, footnote b).

b All mutants were cloned into the BamHI site of pACYC184 of pBR322.

- See Table I, footnote c.

d Correspond to '\% repression' in Table I, footnote $\mathrm{d}$, calculated from the $+\mathrm{L}-\mathrm{W}$ column.

- See Table II, footnote e.

in the TrpR has not been shown to be directly involved in DNA binding, however, Kelley and Yanofsky (1985) proposed that mutations at this position might distort the helix E sufficiently to prevent stable DNA binding of the repressor. On the other hand, TrpR with Trp or Arg substitutions at position 85 are assumed to have some repressor activity due to the effect of these bulky residues placed near the L-W binding pocket. Lys or Glu residues at this position, while possibly too small to prevent the collapse of the repressor dimer, may still be too large to allow proper binding of the co-repressor. This in turn would prevent DNA binding by such mutated repressors.

\section{(b) Mutant-mutant interaction}

Subcloning of different trpR mutant Bam HI fragments in pACYC184 $\left(\mathrm{Cm}^{\mathrm{R}}\right)$ and pBR322 $\left(\mathrm{Ap}^{\mathrm{R}}\right)$ permitted us to introduce two trpR alleles into the same strain and to study possible genetic complementation. Double antibiotic selection was used to maintain the two plasmids. Cells containing the plasmid pACYCl 84 in addition to a copy of the wt trp $R$ gene cloned in $\mathrm{pBR} 322$, served as control. Under these conditions of high copy number plasmids, G85W was found not to be negatively complementing to the wt or to the superrepressor E49K (Table II). However, G85W was found to be negatively complementing to the wt when the wt allele was encoded in the chromosome (Table IV).

The repressor activity in the cells transformed with two $\operatorname{trpR} \mathrm{G} 85 \mathrm{~W}$ genes was higher than in the cells containing only one $t r p R$ G85W gene (Table II), indicating that increased gene copy number caused increased repressor ac- tivity. Such an increase in repressor activity was also seen when G85W and G85R were expressed in the same cell (Table II). Presumably, these TrpR mutants do not satu-

\section{TABLE IV}

The repressor activity of $\operatorname{trp} R$ double mutants in two related strains

\begin{tabular}{llllc}
\hline No." & TrpR & Plasmid $^{b}$ & CY15075 $^{c}$ & CY15050 $^{\text {a }}$ \\
\hline I & none & pACYC184 & 8458 & 15 \\
2 & R $^{+}$ & pACYC184 & 6 & 3 \\
3 & G85W & pACYC184 & 1713 & 84 \\
4 & G85W-T44M & pBR322 & 8849 & 422 \\
5 & G85R-T44M & pACYC184 & 8995 & 510 \\
6 & G85E-T44M & pBR322 & 9938 & 188 \\
7 & G85K-T44M & pACYC184 & 7902 & 338 \\
\hline
\end{tabular}

a Mutants 4-7 were constructed as described by Su and El-Gewely (1988). A mutagenic primer complementary to the $(+)$ strand of M13mpl9trpR was prepared on Pharmacia Gene Assembler Plus synthesizer with the internal CGT $\left(\mathrm{Thr}^{44}\right)$ replaced by CAT (Met): 5 ' -GCTCATCTGGCATCAGCATCAGG-3', and annealed to the $(+)$ strand of the M13trpR deriwatives with G85W, G85R, G85E or G85K and DNA synthesis of the (-) strand was performed. Subcloning and sequencing as in Table I, footnote a.

b Two related strains CY15075 (see Table I, footnote b) and CY15050

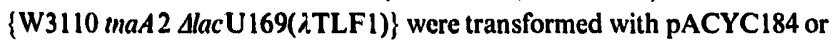
pBR322 carrying the trpR gene containing mutations in both 44 and 85 positions.

c Units of $\beta$ Gal in CY15075 that only produce the mutant repressor.

d Units of $\beta \mathrm{Gal}$ in $\mathrm{CY} 15050$ that also produce the wt repressor. All $\beta \mathrm{Gal}$ assays were made in the presence of L-tryptophan. $\mathrm{Cm}(15 \mu \mathrm{g} / \mathrm{ml})$ or Ap $(20 \mu \mathrm{g} / \mathrm{ml})$, and L-tryptophan $(20 \mu \mathrm{g} / \mathrm{ml})$ were added to the glucose minimal media containing $0.2 \%$ acid-hydrolyzed casein. All assays were made in triplicate and repeated twice. 
rate the trp operator as seems to be the case with the wt repressor. Multicopy wt TrpR expressed in a strain containing a chromosomal $t r p R$ gene, does not increase repression (Table IV). Additional copies of a weak TrpR mutant, such as G85E when combined with G85W, repress at approximately the same level as G85W alone (Table II).

The trpR mutants T44M and G78S had very low activity (Table II). When either of these two mutants was combined with $\mathrm{G85W}$, the repressor activity of the combinations (G85W/G78S and G85W/T44M) increased 14- and 40fold, respectively (Table II). Because both position 85 and position T44M are part of the L-W binding pocket (Zhang et al., 1987), the interactions between these positions were further studied.

Plasmids with the mutant $t r p R$ alleles containing $\mathrm{Arg}^{85}$, $\mathrm{Glu}^{85}$ or $\mathrm{Lys}^{85}$ were introduced into cells expressing trpR T44M. When the trpR T44M mutant was combined with IrpR G85W the repressor function was reconstituted to a level approaching that of the wt, and the :epressor activity was dependent on the presence of L-W ( Table III). This presumably reflects intragenic complemuntation between trp G85W and trp T44M. Similar repressor activity was observed with the combinations G85R/T44M and G85K/ T44M while the G85E/T44M combination showed very low activity (Table III). Heterodimers with a substitution at position 85 in one polypeptide subunit and a T44M substitution in the other polypeptide would lead to repressors containing one mutated and one wt co-repressorbinding pocket. The fact that the G85E/T44M combination did not show significant repressor activity, while the G85W/T44M, G85R/T44M and G85K/T44M combinations did, suggests that the observed repressor activity of these dimers is due to their specific mutations and not due to the wt co-repressor-binding pocket. Also, the different levels of repression between G85W/T44M, G85R/T44M and $\mathrm{G} 85 \mathrm{~K} / \mathrm{T} 44 \mathrm{M}$ (Table III) reflect the importance of the specific mutations in the co-repressor-binding pocket. The importance of the specific residues in the co-repressorbinding pocket is also supported by the fact that different mutants affecting position 85 (G85E, G85K and G85R) exhibited different degrees of negative complementation to the $\operatorname{trp} R \mathrm{wt}$ allele as reported earlier by Kelley and Yanofsky (1985).

The strain used to test intragenic complementation is $\operatorname{recA} A^{+}$and theoretically this could introduce recombination between the different trp alleles, causing ambiguity in the $\beta G$ al assays. However, recombination would result in double mutants that had lost repressor activity (Table IV) as well as wt repressors. Any mutant without repressor activity would be seen as deep blue colonies on the indicator plates testing intragenic complementation. This was not observed, reflecting that interallelic recombination between aa positions 44 and 85 is a rare event. (c) trpR double mutants

Double mutants containing $T 44 \mathrm{M}$ and a substitution at aa position 85 (G85W, G85R, G85K or G85E) in the same gene, resulted in a total loss of repressor activity. All of these double mutants negatively complemented the wt (Table IV).

The individual subunits of TrpR do not have the compact or 'globular' shape typical of most proteins and subunits (Schevitz et al., 1985). The tertiary structural interactions are provided primarily by contacts between the monomers. This poses the question of how the newly synthesized monomer folds and is stabilized before dimerization (Schevitz et al., 1985). Two mutations in the same polypeptide chain may negatively affect the folding process or the stability of the folded structure of the monomer, thereby preventing proper dimer formation. The different levels of negative complementation to the wt (Table IV) could suggest different degrees of folding problems. In the cases of second-site revertants, the situation is different since the mutants are selected for their improved function. One mutation, either at position 85 or position 44, may have a negligible effect on the folding mechanism.

Intragenic complementation, known also as intracistronic and interallelic complementation, has been reported in many systems (Fincham, 1966; Zabin and Villarejo, 1975). However, its utilization as a powerful genetic tool to study protein folding, protein-protein interaction, and structure-function relationship in the case of multimeric proteins, has not been fully developed. Genetic approaches to study structure-function interaction have focused mainly on studies dealing with second site reversion (Hecht and Sauer, 1985; Nelson and Sauer, 1985) or negative complementation (Adler et al., 1972; Miller, 1978). The TrpR was previously subjected to such genetic analysis (Kelley and Yanofsky, 1985; Klig et al., 1988a,b). With the current knowledge of recombinant DNA technology and crystal structure of several proteins, intragenic complementation may offer clues to some of the rules of protein folding and protein structure-function relationship.

\section{(d) Conclusions}

(1) G85W mutant has weak but significant repressur activity that is independent of $\mathrm{L}-\mathrm{W}$ in the media. G85W negatively complements the wt allele, but it does not negatively complement the wt expressed in a multiple copy plasmid.

(2) Intragenic complementation was observed only when certain mutants affecting the $\mathrm{L}-\mathrm{W}$ binding pockets were combined in vivo. If the mutant $T 44 \mathrm{M}$ is fixed in all the interactions, the alleles G85W, G85R, and G85K can restore wt repressor activity. This activity is $\mathrm{L}-\mathrm{W}$-dependent.

(3) In this experiment, a positive charge $(R, K)$ or an indole ring (W), appears to be needed for intragenic com- 
plementation, while a negative charge (E) does not exhibit intragenic complementation.

(4) All of the interacting mutants described above (G85W/T44M, G85R/T44M, G85K/T44M and G85E/ T44M), have a potential wt L-W-binding pocket (fixed). However, their repressor activity varies significantly due to the specific interacting residues in the other binding pocket.

(5) Double mutants that contain one mutation at position 85 and a T44M mutation, have lost repressor activity which may be due to a folding problem.

(6) Mutant-mutant interaction and intragenic complementation offer additional genetic tools to study the structure-function relationship of dimer proteins.

\section{ACKNOWLEDGEMENTS}

We would like to thank Ingrid Bakke for technical help. N.S. is a recipient of an NAVF fellowship. This work is supported by a grant from Norwegian Research Council for Science and the Humanities (NAVF) to M.R.El-G. Part of this work was also supported by National Institute of Health grant GM20737 to D.L.O.

\section{REFERENCES}

Adler, K., Beyreuther, K., Fanning, E., Geisler, N., Gronenborn, B., Klemm, A., Muller-Hill, B., Pfahl, M. and Schmitz, A.: How lac repressor binds to DNA. Nature 237 (1972) 322-327.

Arvidson, D.N., Bruce, C. and Gunsulus, R.P.: Interaction of the Escherichia coli trp aporepressor with its ligand, L-tryptophan. J. Biol. Chem. 261 (1986) 238-243.

Biggin, M.D., Gibson, T.J, and Hong, G.F.: Buffer gradient gels and ${ }^{35} \mathrm{~S}$ label as an aid to rapid DNA sequence determination. Proc. Natl. Acad. Sci. USA 80 (1983) 3963-3965.

Birnboim, H.C. and Doly, J.: A rapid alkaline extraction procedure for screening recombinant plasmid DNA. Nucleic Acids Res. 7 (1979) 1513-1523.

Bolivar, F., Rodriguez, R.L., Greene, P.J., Betlach, M.C., Heyneker, H.L., Boyer, H.W., Crosa, J.H. and Falkow. S.: Construction and characterization of new cloning vehicles. II. A multipurpose cloning system. Gene 2 (1977) 95-113.

Chang, A.C.Y. and Cohen, S.N.: Construction and characterization of amplifiable multicopy DNA cloning vehicles derived from the P15A cryptic miniplasmid. J. Bacteriol. 134 (1978) 1141-1166.

El-Gewely, M.R.: Faster CsCl-ethidium bromide density gradient centrifugation technique. DNA Prot. Eng. Tech. 1 (1988) 17-20.

El-Gewely, M.R.: A genetic approach to study the structure-function relationship of tryptophan repressor. In: El-Gewely, M.R. (Ed.), Sitedirected Mutagenesis and Protein Engineering. Elsevier, Amsterdam, 1991, pp. 141-153.

Fincham, J.R.S.: Genetic Complementation. Benjamin, New York, 1966.

Gehring, W.J., Muller, M., Affolter. M., Percival-Smith, A., Billeter, M., Qian, Y.Q., Otting, G. and Wüthrich, K.: The structure of the homeodomain and its functional implications. Trends Genet. 6 (1990) 323328.

Girvitz, S.C., Bacchetti, S., Rainbow, A.J. and Graham, F.L.: A rapid and efficient procedure for the purification of DNA from agarose gels. Anal. Biochem. 106 (1980) 492-496.

Graddis, T.J., Klig, L.S., Yañofisy, C. and Oxender, D.L.: Formation of heterodimers between wild type and mutant trp aporepressor polypeptides of Escherichia coli. Proteins 4 (1988) 173-181.

Grove, C.L. and Gunsalus, R.P.: Regulation of the aroH operon of Escherichia coli by tryptophan repressor. J. Bacteriol. 169 (1987) 2158-2164.

Gunsalus, R.P. and Yanofsky, C.: Nucleotide sequence and expression of Escherichia coli trpR, the structural gene of the trp aporepressor. Proc. Natl. Acad. Sci. USA 77 (1980) 7117-7121.

Harrison, S.C. and Aggarwal, A.K.: DNA recognition by proteins with the helix- turn-helix motif. Annu. Rev. Biochem. 59 (1990) 933-969.

Heatwole, V.M. and Somerville, R.L.: The tryptophan-specific permease gene, $m i r$, is differentially regulated by the tryptophan and tyrosine repressors in Escherichia coli K-12. J. Bacteriol. 173 (1991) 36013604.

Hecht, M.H. and Sauer, R.T.: Phage lambda repressor revertants: amino acid substitutions that restore activity to mutant proteins. J. Mol. Biol. 186 (1985) 53-63.

Joachimiak, A., Kelley, R.L. Gunsalus, R.P., Yanofsky, C. and Sigler, P. B.: Purification and characterization of trp aporepressor. Proc. Natl. Acad. Sci. USA 80 (1983) 668-672.

Kelley, R.L. and Yanofsky, C.: Mutational studies with the $t r p$ repressor of Escherichia coli support the helix-turn-helix model of repressor recognition of operator DNA. Froc. Natl. Acad. Sci. USA 82 (1985) 483-487.

Klig, L.S., Carey, J. and Yanofsky, C.: Trp repressor interactions with the $t r p, a r o H$, and the $t r p R$ operators. Comparison of repressor binding in vitro and repression in vivo. J. Mol. Biol. 202 (1988a) 769-777.

Klig, L.S., Oxender. D.L. and Yanofsky, C.: Second-site revertants of Escherichia coli trp repressor mutants. Genetics 120 (1988b) 651-655.

Kunkel, T.A.: Rapid and efficient site-specific mutagenesis without phenotypic sclection. Proc. Natl. Acad. Sci. USA 82 (1985) 488-492.

Kunkel, T.A., Roberts, J.D. and Zakour, R.A.: Rapid and efficient sitespecific mutagenesis without phenotypic selection. Methods Enzymol. 154 (1987) 367-382.

Lawson, C.L. and Sigler, P.B.: The structure of trp pseudorepressor at $1.65 \AA$ shows why indole propionate acts as a trp 'inducer'. Nature 333 (1988) 869-871.

Lehming, N., Sartorius, J., Kisters-Woike, B., von Wilcken-Bergmann, B. and Muller-Hill, B.: Mutant lac repressors with new specificities hint at rules for DNA-protein recognition. EMBO J. 9 (1990) 615621.

Maniatis, T., Hardison. R.C., Lacy, E., Lauer, J., O'Connell, C., Quon, D., Sim, G.K. and Efstratiadis, A.: The isolation of structural genes from libraries of eucaryotic DNA. Cell 15 (1978) 687-701.

Marmorstein, R.Q. and Sigler, P.B.: Stereochemical effects of Ltryptophan and its analogues on $t r p$ repressor's affinity for opere: 0 DNA. J. Biol. Chem. 264 (1989) 9149-9154.

Marmorstein, R.Q., Joachimiak, A., Sprinzl, M. and Sigler, P.B.: The structural basis for the interaction between L-tryptophan and the Escherichia coli trp aporepressor. J. Biol. Chem. 262 (1987) 49224927.

Messing, J.: New M13 vectors for cloning. Methods Enzymol. 101 (1983) 20-78.

Miller, J.H.: Experiments in Molecular Genetics. Cold Spring Harbor Laboratory, Cold Spring Harbor, NY, 1972.

Miller, J.H.: The lacl gene: its role in lac operon control and its use as a genetic system. In: Miller, J.H. and Reznikoff, W.S. (Eds.), The Operon. Cold Spring Harbor Laboratory, Cold Spring Harbor, NY, 1978, pp. 31-88.

Nelson, H.C.M. and Sauer, R.T.: Lambda repressor mutations that in- 
crease the affinity and specificity of operator binding. Cell 42 (1985) 549-558.

Otwinowski, Z., Schevitz, R.W., Zhang, R.-G., Lawson, C.L., Joachimiak, A., Marmorstein, R.Q., Luisi, B.F. and Sigler, P.B.: Crystal structure of $t r p$ repressor/operator complex at atomic resolution. Nature 335 (1988) 321-329.

Pabo, C.O. and Sauer, R.T.: Protein-DNA recognition. Annu. Rev. Biochem. 53 (1984) 293-321.

Sanger, F. and Coulson, A.R.: The use of thin acrylamide gels for DNA sequencing. FEBS Lett. 87 (1978) 107-110.

Sanger, F., Nicklen, S. and Coulson, A.R.: DNA sequencing with chainterminating inhibitors. Proc. Natl. Acad. Sci. USA 74 (1977) 54635467.

Sarsero, J.P., Wookey, P.J. and Pittard, A.J. Regulation of expression of the Escherichia coli K-12 mtr gene by TyrR protein and Trp repressor. J. Bacteriol. 173 (1991) 4133-4143.

Schevitz, R.W., Otwinowski, Z., Joachimiak, A., Lawson, C.L. and Sigler, P.B.: The three-dimensional structure of trp repressor. Nature 317 (1985) 782-786.

Scott, M.P., Tamkun, J.W. and Hartzell III, G.W.: The structure and function of the homeodomain. Biochim. Biophys. Acta 989 (1989) 25-48.
Staacke, D., Walter, B., Kisters-Woike, B., von Wilcken-Bergmann, B. and Maller-Hill, B.: How Trp repressor binds to its operator. EMBO J. 9 (1990) 1963-1967.

Su, T.-Z. and El-Gewely, M.R.: A multisite-directed mutagenesis using T7 DNA polymerase: application for reconstructing a mammalian gene. Gene 69 (1988) 81-89.

Vogel, H.J. and Bonner, D.M.: Acetylornithinase of Escherichia coli: partial purification and some properties. J. Biol. Chem. 218 (1956) 97106.

Yanisch-Perron, C., Vieira, J. and Messing, J.: Improved M13 phage cloning vectors and host strains: nucleotide sequences of the M13mp18 and pUC19 vectors. Gene 33 (1985) 103-119.

Yanofsky, C. and Horn, V.: Rifampicin resistance mutations that alter the efficiency of transcription termination at the tryptophan operon attenuator. J. Bacteriol. 145 (1981) 1334-1341.

Zabin, I. and Villarejo, M.R.: Protein complementation. Annu. Rev. Biochem. 44 (1975) 293-313.

Zhang, R.G., Joachimiak, A., Lawson, C.L., Schevitz, R.W., Otwinowski, Z. and Sigler, P.B.: The crystal structure of trp aporepressor at $1.8 \AA$ shows how binding tryptophan enhances DNA affinity. Nature 327 (1987) 591-597. 